\title{
Are body circumferences able to predict strength, muscle mass and bone characteristics in obesity? A preliminary study in women
}

\author{
Valentina Cavedon, Chiara Milanese, and Carlo Zancanaro ${ }^{\bowtie}$ \\ Laboratory of Anthropometry and Body Composition, Department of Neurosciences, Biomedicine and Movement Sciences, University of Verona, Verona, Italy \\ $\triangle$ Corresponding author: Carlo Zancanaro, M.D., DNBM, Strada Le Grazie 8, I-37134 Verona, ITALY. Tel. +390458027155; Fax +390458027163; e-mail: \\ carlo.zancanaro@univr.it \\ (C) The author(s). This is an open access article distributed under the terms of the Creative Commons Attribution License (https://creativecommons.org/licenses/by/4.0/). \\ See http://ivyspring.com/terms for full terms and conditions.
}

Received: 2019.11.01; Accepted: 2020.02.18; Published: 2020.03.15

\begin{abstract}
Measurement of body circumferences (BCs) is widely used as an anthropometric tool to assess body composition and health risk in obese individuals. In this preliminary work we evaluated the association of several BCs with Dual-energy X-ray Absorptiometry (DXA)-measured lean mass as well as leg press test scores with an aim at exploring the potential of BCs as predictor of body composition and muscle strength. A total of 34 female participants aged $47.3 \pm 7.6$ y who were obese (BMI, 30.4-43.7 kg/m²) were recruited. The upper arm (relaxed), wrist, chest, waist, hip, thigh, and calf circumferences were measured. The skinfold-corrected muscle (including bone) circumferences at the arm, thigh, and calf site were also calculated. Lean mass components were measured by DXA with a Hologic QDR Explorer scanner according to the manufacturer's procedures. Lower limbs strength was assessed with the 1-Repetition Maximum leg press. Bivariate association between variables was assessed with the Spearman's correlation coefficient after the Benjamini and Hochberg False Discovery Rate procedure. Predictive equations were developed using stepwise multiple regression analysis. Several statistically significant correlations (Benjamini and Hochberg corrected $\mathrm{P}\left[\mathrm{P}_{\mathrm{c}}\right]<0.05$ ) were present between $\mathrm{BCs}$ and DXA-measured body composition variables, and leg press test scores with special regard to the chest, arm, waist, and hip circumferences. Multiple regression analysis yielded statistically significant predictive models $\left(P_{c}<0.05\right.$ for all; adjusted $R^{2}$ ranging $0.123-0.504$; standard error of the estimate ranging $4.0 \%$ $11 \%$ of the mean measured value) for all body composition as well as leg press outcomes. The current findings show that BCs represent a simple, suitable anthropometric measurement with a potential to predict several lean mass components as well as lower limbs strength in obese females. The proposed predictors need to be validated in a larger sample of participants and in obese males.
\end{abstract}

Key words: anthropometry, body composition, mineral mass, mineral density, linear regression, prediction equation

\section{Introduction}

The large majority of lean body mass i.e., the metabolically active component of the body is represented by skeletal muscle playing a key role in a number of physiologic processes [1]. In turn, the large majority of skeletal muscle is appendicular (about $75 \%$ of total) with the lower limbs containing about $55 \%$ of the body skeletal muscle [2,3]. When assessing skeletal muscle, both the absolute amount of muscle tissue (i.e., muscle mass) and the ability of muscle to generate strength (i.e., muscle quality) should be considered, because skeletal muscle mass and strength may not parallel in individuals [4].

In obesity, reliable assessment of skeletal muscle mass and strength would be relevant for both patients and physicians. For example, skeletal muscle mass is a major responsible for glucose uptake under insulin-stimulated conditions, thereby strongly affecting insulin sensitivity, which is frequently altered in obesity. Further, appendicular muscle mass is associated with mobility and functional 
independence, which may be a factor affecting the quality of life of obese people [5]. On the other hand, muscle strength is an important component of physical function [6] and may affect habitual physical activity [7]. Overall, assessing muscle mass and strength in obese persons could help evaluating their general physical conditions as well as providing an estimate of healthy and active lifestyle. Moreover, results of strength assessment could be useful for the monitoring of exercise programs for obese patients.

Traditionally, obesity is thought to be beneficial to bone in terms of bone mineral density (BMD) and/or content (BMC) via increased mechanical loading associated with higher fat mass and/or the extra strain imposed on bone by increased muscle mass [8]; however, it has been suggested that locomotion-induced ground reaction forces and accompanying muscle contractions are sufficient to improve bone strength [9]. Accordingly, the relationships between body mass, body composition and bone mass/quality are complex [10] and the impact of obesity on bone status is not completely clarified, the effects of body fat and lean mass on bone being possibly different [11]. However, independently of the actual mechanism(s) mediating the relationship between body composition and bone, estimation of bone characteristics in obesity would be a useful complement to the routine evaluation of patients with special reference to females, which are at increased risk of osteoporosis.

Dual-energy X-ray Absorptiometry (DXA) is able to accurately assess lean mass (distinguishing between the mass of lean soft tissue, LST, and mineral mass) at the whole body (WB) and regional level. The areal BMD is also included in the standard DXA output. The limb LST mass, BMC, and BMD can be easily obtained from DXA readings (Fig. 1). The sum of LST mass in the four limbs i.e., appendicular LST mass is used as a surrogate of skeletal muscle mass, and DXA estimates of appendicular LST mass have been validated against skeletal muscle mass measurements obtained with magnetic resonance imaging and computed tomography $[3,12,13]$. As far as muscle strength is concerned, isotonic muscle strength can be measured using several techniques, one of the most commonly used being the One Repetition Maximum (1-RM) technique. The Repetition Maximum represents the maximum number of repetitions performed before fatigue prohibits completion of an additional repetition and generally reflects the intensity of the exercise [14]. However, both DXA and 1-RM are laboratory-based techniques, which are unpractical for use in large or field studies due to their relatively high costs and logistics required to perform measurements. Further,
DXA employs $X$-ray radiation, which may hamper its widespread use, and 1-RM may be harmful to joint and muscle when measuring maximum muscle strength in persons with low muscular strength. According to the considerations above, there is a need for a non-invasive, cheap, and repeatable tool to estimate lean mass components and muscle strength in obesity.

Body circumferences (BCs) are simple to measure, inexpensive and non-invasive, and require minimum instrumentation (just an anthropometry tape) while yielding accurate data when performed by a trained operator according to standard procedures [15]. Moreover, BCs can easily be used in field studies as well as the clinical setting. In addition to the ease of measurement, BCs have fewer problems with measurement error vs. skinfold thickness, especially in persons with obesity [16].

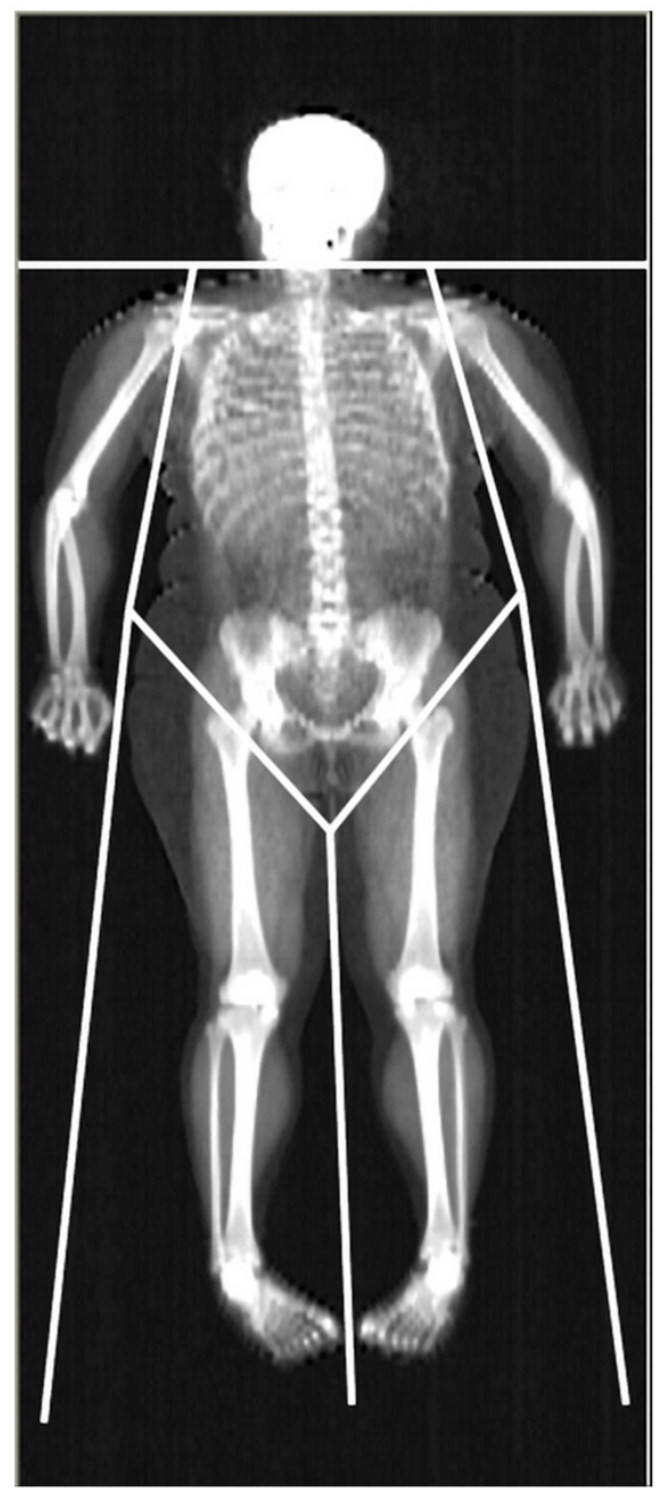

Figure 1. Representative whole-body DXA scan. The limits defining the regions of interest used in this work (upper and lower limb, trunk) are depicted. 
Several BCs have been used to estimate WB muscle mass as well as muscle strength especially the mid-arm, mid-thigh, and maximum calf circumference [15, 17-21]. Anthropometric predictive equations have been developed for appendicular muscle mass [21-26]. The association between bone mineral mass and density, and anthropometry has been explored as well leading to derivation of predictive anthropometric equations for bone [27-29]. More recently, it has been shown that calf circumference is able to predict BMD in older adults [30], arm circumference at muscle flexion is predictive of lumbar spine BMD [31] and waist circumference is inversely associated with BMD in male and female Koreans $>50 \mathrm{y}$ after adjusting for several confounders [32]. However, the predictive equations above were generated in the general population or in populations with special characteristics and may be not accurate in obese patients. In summary, validating BCs as estimators of muscle mass and strength as well as bone characteristics in obesity would be of use to physicians, researchers, and patients.

In this preliminary work, a group of obese females underwent BC measurements, DXA body composition analysis, and lower limbs strength tests with an aim at exploring the following hypotheses: 1 . BCs are associated with LST mass of the limbs (a proxy of appendicular skeletal muscle) and muscle strength as well bone mineral characteristics, and 2 . $\mathrm{BCs}$ are suitable predictors of lean mass variables and muscle strength.

\section{Materials and Methods}

\section{Participants}

Thirty-four Caucasian adult female obese (body mass index, BMI $>30 \mathrm{~kg} / \mathrm{m}^{2}$ ) outpatients (age range $35-61 y ; 38 \%$ postmenopausal) previously submitted to lifestyle counselling and with body weight stable over the last three months participated in this study. No patients suffered from diabetes or other significant disease nor had history of osteoporosis; none of them had been taking medications in the last six months that could potentially interfere with the evaluations carried out in the study. This study was carried out in accordance with the recommendations of the Helsinki Declaration with written informed consent obtained from all participants. The study protocol was approved by the Institutional Review Board at the University of Verona.

\section{Anthropometry}

Body mass and stature were taken at the nearest $0.1 \mathrm{~kg}$ and $0.01 \mathrm{~m}$ with a Tanita electronic scale BWB-800 MA (Wunder SA.BI. Srl) and a stadiometer (Holtain Ltd., Crymych, Pembs. UK), respectively.
Body circumferences were measured at the upper arm (relaxed), wrist, chest, waist, hip, thigh and calf site according to standard procedures [33]. Since skinfold-corrected limb circumferences may provide a measure of corresponding appendicular lean limb circumference $[17,19,20]$, the arm, thigh, and calf circumferences were corrected for subcutaneous adipose tissue thickness. Skinfold thickness was taken at the triceps, anterior thigh, and calf site according to standard procedures [34]. The corrected muscle (including bone) circumferences were calculated as $\mathrm{Cm}=\mathrm{C}_{\text {limb }}-\Pi \mathrm{S} / 10$, where $\mathrm{Cm}=$ corrected muscle circumference, $\mathrm{C}_{\text {limb }}=$ limb circumference $(\mathrm{cm})$, and $\mathrm{S}$ $=$ skinfold thickness $(\mathrm{mm})$, assumed to be twice the subcutaneous adipose tissue thickness. The percent technical error of measurement was $<1.0 \%$ for BCs and $<3.5 \%$ for skinfolds recorded in this study and therefore within acceptable limits (i.e., $<5.0 \%$ for skinfold thickness and $<1.0 \%$ for all other measures) [34].

\section{Body composition analysis}

Body composition was evaluated by means of DXA (QDR Explorer W, Hologic, MA, USA; fan-bean technology, software for Windows XP version 12.6.1) according to the manufacturer's procedures. The scanner was quality-checked daily against the standard supplied by the manufacturer to avoid possible baseline drift. In our laboratory, the precision error (percent coefficient of variation with repositioning) of whole body (WB) DXA measurements is $1.1 \%, 0.9 \%$, $2.3 \%, 2.8 \%$ and $0.5 \%$ for $\mathrm{BMC}, \mathrm{BMD}$, fat mass (FM), percentage fat mass (\%FM) and LST mass, respectively. The same operator performed all scanning and analysis to ensure consistency.

For the standard regional body composition estimations, Hologic software readings divided the body into trunk, entire upper limb, entire lower limb, and head (Fig. 1).

$\mathrm{BMC}$ is preferable to BMD as bone health outcome. Actually, BMD is more prone to measurement error because DXA measures areal, not volumetric, BMD. Accordingly, BMD may artificially over- or underestimate the relative bone mass according to the individual's bone size [35]. Moreover, systematic inaccuracies in BMD measurement with DXA may ensue [36]. Therefore, BMC was considered the main index of bone quality in this work; however, in order to allow comparison with most of the previous relevant literature, BMD data are also presented and discussed. The WB less head (WBLH) DXA measurements for BMC and BMD were used as dependent variable in regression analysis (vide infra) instead of $\mathrm{WB}$ values with an aim at increasing precision. In fact, the skull has a relatively large impact on the WB BMC and BMD due to its 
large content in compact bone; however, the skull is not involved in weight bearing and correlation of head BMD with that of other parts of the skeleton is far from perfect [37]; moreover, changes in bone density of the head with age and BMI differ to that of the rest of the skeleton [38]. WBLH measurements were taken by excluding the head from the rest of the body by a plane at $90^{\circ}$ to the long axis of the body, immediately caudally to the mandible. In this study, LST mass and FM as well as BMC and BMD values, and \%FM were also calculated for the right and left upper limbs combined (region: upper limbs), the right and left lower limbs combined (region: lower limbs), and the upper and lower limbs combined (region: appendicular).

\section{Strength test}

The maximum dynamic strength of lower limbs was determined on leg press test (Personal Selection TÜV, Technogym, Italy). The 1-RM method was used. The initial load for the 1-RM test was predicted from $50 \%$ of body weight. After a warm-up of 5 minutes walking at self-selected speeds on a treadmill followed by one set of 10 repetitions at a relatively light load, each participant performed a single repetition with a weight she could lift through a complete range of motion. At the conclusion of each successful lift, a higher load (2.5-5.0\%) for a second trial was added. A recovery period of one minute was allowed between lifts. This procedure was repeated until the participant could no longer lift the weight (achieved in 3 to 6 attempts). The greatest amount of weight lifted successfully was recorded as the 1-RM, and the test's score was determined with the formula [lifted load/1.0278 - (0.0278 x numbers of repetition)] [39]. Strength relative to whole body mass and LST mass was calculated as the test's score $(\mathrm{kg})$ divided by whole body mass $(\mathrm{kg})$ and by DXA-measured LST mass $(\mathrm{kg})$, respectively.

\section{Statistical analysis}

Normality of data was checked with the Shapiro-Wilks test. Data were summarized as mean \pm standard deviation and median (interquartile range) for normally and non-normally distributed variables, respectively. Bivariate and partial association between variables was assessed with the Spearman's correlation coefficient, $\rho$. The strength of the correlation coefficient was considered small $(0-0.30)$, moderate $(0.31-0.49)$, large $(0.50-0.69)$, very large (0.70 - 0.89), and almost perfect $(0.90-1)$ as per Hopkins [40]. The Benjamini and Hochberg False Discovery Rate procedure was used to get corrected p-value $\left(p_{c}\right)$, in order to minimize Type I error associated with multiplicity of correlations in the same dataset [41]. False Discovery Rate was set at 0.05 .

Stepwise regression analyses were conducted with DXA-measured outcomes or strength tests scores as the dependent variable and a maximum of three body circumferences showing the highest significant $\left(\mathrm{P}_{\mathrm{c}}<0.05\right)$ correlation with the dependent variable as the independent variables. The number of predictors in regression analysis was chosen to have a sample size/predictor variable ratio of about ten, which is currently used in regression analysis. The probability of F-to-enter was set at $\leq 0.05$ for inclusion and $\geq 0.10$ for exclusion of predictor variables. Adjusted $\mathrm{R}^{2}$ and SEE were used to assess the goodness of the predictor model.

Homoscedasticity of data was assessed by plotting the residuals of multiple regression analysis against the predicted values as well as the Koenker test [42]. The presence of serial correlations among the residuals was tested using the Durbin-Watson statistic and the variance inflation factor (VIF) was calculated to check for multicollinearity in the multiple linear regression models. Statistical significance was set at $\mathrm{P}$ $\leq 0.05$.

Table 1. Demographic characteristics of the 34 obese females participating in this study.

\begin{tabular}{lll}
\hline Variable & Mean \pm SD / Median (IQ) & Maximum/Minimum \\
\hline Age $\mathbf{( y )}$ & $47.3 \pm 7.6$ & $35-61$ \\
Stature $\mathbf{( c m )}$ & $158.2 \pm 4.3$ & $151-170$ \\
Body mass (kg) & $90.9 \pm 10.6$ & $72.9-109.3$ \\
BMI (kg/m²) & $36.1(8.7)$ & $30.4-43.7$ \\
Normally distributed variables are presented as mean \pm standard deviation, SD); \\
non-normally distributed variables are median (interquartile range, IQ). BMI, Body \\
Mass Index.
\end{tabular}

\section{Results}

\section{Characteristics of participants}

The demographic characteristics of the participants are summarized in Table 1. Out of 34 participants, 13 were Class I obese (BMI 30-34.9 $\left.\mathrm{kg} / \mathrm{m}^{2}\right), 11$ were Class II (BMI $\left.35-39.9 \mathrm{~kg} / \mathrm{m}^{2}\right)$, and 10 were Class III (BMI $\left.\geq 40 \mathrm{~kg} / \mathrm{m}^{2}\right)$ [43]. Median age, stature, and body mass were $47.5 \mathrm{y}, 1.57 \mathrm{~m}$, and 87.85 $\mathrm{kg}$, respectively. No participant was found to be sarcopenic according to the skeletal muscle mass (SMM) index [22]. The SMM index is calculated as the ratio of DXA-measured appendicular LST $(\mathrm{kg})$ and height $(\mathrm{m})^{2}$; the cut-off value for sarcopenia $(\mathrm{SMM}<$ 5.45) corresponds to a SMM index less than two standard deviation below the mean of the reference population i.e., a young female group from the Rosetta study aged 18 to 40 [22]. In our sample of obese females, the mean value of the SMM index was $7.88 \pm 0.92 \mathrm{~kg} / \mathrm{m}^{2}$. The DXA-derived T-score was 
above the current cut-off for osteoporosis $(-2.5)$ in all participants.

Table 2. Body circumferences and DXA-measured body composition of study participants.

\begin{tabular}{|c|c|c|}
\hline Variable & Mean \pm SD $/$ Median (IQ) & Maximum/Minimum \\
\hline \multicolumn{3}{|l|}{ Body circumference $(C)$} \\
\hline Mid-arm C (cm) & $35.1 \pm 2.7$ & $30.0-43.4$ \\
\hline Corrected mid-arm C $(\mathrm{cm})$ & $29.2 \pm 2.5$ & $24.4-36.4$ \\
\hline Wrist $C(\mathrm{~cm})$ & $16.7 \pm 1.2$ & $14.5-19.2$ \\
\hline Chest C (cm) & $103.9 \pm 6.8$ & $93.5-116.0$ \\
\hline Waist C (cm) & $96.5(14.1)$ & $88.0-118.1$ \\
\hline Hip C (cm) & $119.7 \pm 9.6$ & $101.2-143.5$ \\
\hline Waist-to Hip ratio & $0.83 \pm 0.06$ & $0.69-1.01$ \\
\hline Mid-thigh C (cm) & $63.0 \pm 5.9$ & $51.4-79.7$ \\
\hline Corrected mid-thigh $\mathrm{C}(\mathrm{cm})$ & $47.5 \pm 5.1$ & $35.4-63.1$ \\
\hline Calf $C(\mathrm{~cm})$ & $40.5 \pm 3.3$ & $33.2-49.5$ \\
\hline Corrected calf C $(\mathrm{cm})$ & $30.6 \pm 1.7$ & $27.3-34.7$ \\
\hline \multicolumn{3}{|l|}{ DXA measurement } \\
\hline WBLH BMC (g) & $1563.3 \pm 196.1$ & $1173.6-1998.7$ \\
\hline WBLH BMD $\left(\mathrm{g} / \mathrm{cm}^{2}\right)$ & $0.892 \pm 0.062$ & $0.768-1.003$ \\
\hline WBLH LST (g) & $44680.7 \pm 5210.4$ & $36661.6-55656.2$ \\
\hline WBLH FM (g) & $38737.7 \pm 6544.0$ & $27330.0-50718.5$ \\
\hline WBLH FM (\%) & $45.3 \pm 4.2$ & $37.6-52.8$ \\
\hline Upper limbs BMC (g) & $289.4 \pm 36.2$ & $207.8-353.1$ \\
\hline Upper limbs BMD $\left(\mathrm{g} / \mathrm{cm}^{2}\right)$ & $0.717 \pm 0.043$ & $0.621-0.81 .4$ \\
\hline Upper limbs LST (g) & $4417.5 \pm 739.8$ & $3500.4-6404-3$ \\
\hline Upper limbs FM (g) & $5314.2 \pm 1165.1$ & $3220.3-7486.6$ \\
\hline Upper limbs FM (\%) & $52.1 \pm 5.9$ & $40.0-63.6$ \\
\hline Lower limbs BMC (g) & $721.9 \pm 100.9$ & $538.2-979.1$ \\
\hline Lower limbs BMD $\left(\mathrm{g} / \mathrm{cm}^{2}\right)$ & $1.062 \pm 0.086$ & $0.903-1.234$ \\
\hline Lower limbs LST (g) & $15182.8 \pm 2005.7$ & 11898.8 - 19649.3 \\
\hline Lower limbs FM (g) & $13179.0 \pm 3930.2$ & $6508.9-22446.7$ \\
\hline Lower limbs FM (\%) & $44.4 \pm 6.8$ & $28.7-57.3$ \\
\hline Appendicular BMC (g) & $1011.3 \pm 125.1$ & $766.5-559.3$ \\
\hline Appendicular BMD $\left(\mathrm{g} / \mathrm{cm}^{2}\right)$ & $0.933 \pm 0.075$ & $0.807-1.045$ \\
\hline Appendicular LST (g) & $19700.2 \pm 2439.6$ & $15629.7-26053.6$ \\
\hline Appendicular FM (g) & $18493.2 \pm 4148.2$ & $11016.5-28341-5$ \\
\hline Appendicular FM (\%) & $46.6 \pm 5.6$ & $33.8-58.0$ \\
\hline
\end{tabular}

Normally distributed variables are presented as mean \pm standard deviation, SD); non-normally distributed variables are median (interquartile range, IQ). BMC, Bone Mineral Content; BMD, Bone Mineral Density; LST, Lean Soft Tissue; FM, Fat Mass; WBLH, Whole-Body Less Head.

Table 3. Results (mean \pm standard deviation, SD) of leg press strength test in the study participants.

\begin{tabular}{lll}
\hline Variable & Mean \pm SD & Minimum/Maximum \\
\hline Leg press (kg) & $191.4 \pm 44.5$ & $127.1-318.0$ \\
\hline
\end{tabular}

\section{Body composition analysis and strength test outcomes}

The results of DXA measurements are reported in Table 2.

The results of leg press test are presented in Table 3. When the sample of obese females was subdivided according to median age $(<48 \mathrm{y}, \mathrm{n}=18$; $>$ $48 \mathrm{y}, \mathrm{n}=16$ ), average scores in strength tests were lower in older participants, but the difference was not statistically significant $(202.3 \pm 51.0 \mathrm{~kg}$ vs. $179.1 \pm 33.1$ $\mathrm{kg}, \mathrm{P}=0.130$ ).

\section{Correlation between BCs, body composition and leg press test}

After Benjamini \& Hochberg correction, P values $\leq 0.025$ were considered significant $\left(P_{c} \leq 0.05\right)$. Bivariate correlations between body composition and muscle strength variables, and BCs are presented in Table 4. Several statistically significant $\left(\mathrm{P}_{\mathrm{c}}<0.05\right)$ correlations were found between $\mathrm{BCs}$ and DXA-measured body composition variables and lower limbs strength tests scores. The larger number of significant correlations was found for the chest circumference (12 out of 15 body composition variables and the strength test scores), the arm and waist circumference (10/15), and the hip circumference $(7 / 15)$. The pattern of association between selected measurement outcomes and BCs is graphically depicted in Fig. 2. Relative strength expressed either as leg press score/whole body mass or leg press score/LST mass did not show any significant correlation with BCs. Similar findings were obtained after adjusting for age.

Trunk circumferences (chest, waist, hip) showed stronger correlation with limb LST masses than regional with the exception of wrist circumference showing the strongest correlation with upper limbs LST. Upper and lower limbs LST did not significantly correlate with the corrected arm and corrected calf circumference, respectively.

WBLH BMC showed positive, large-to-moderate correlation with the chest, arm, and corrected arm circumference. Appendicular BMC showed the strongest correlation with the corrected arm circumference. Upper limbs BMC moderately correlated with the wrist circumference. Lower limbs BMC did not significantly correlate with regional circumferences. All BMD variables showed their strongest positive correlation with one of the trunk circumferences. No significant correlation was found between lower limbs BMD and the regional circumferences. Leg press scores showed large correlation with the chest and waist circumferences but were not significantly correlated with regional circumferences.

Most correlations between BCs and the measured outcomes were still significant after controlling for participants' age. In several instances, the strength of correlation increased after adjusting for age or correlation become statistically significant (Table 4).

\section{Regression analysis}

The results of stepwise linear regression analyses are reported in Table 5. A statistically significant model was developed for all dependent variables using one or two BCs. Models explained about 30 to $50 \%$ of variance for TBLH and regional, $12.3-27.3 \%$ of variance for BMC variables, $33.3-42.8 \%$ of variance 
for TBLH, appendicular, and upper and lower limbs $\mathrm{BMD}$, and $43.1 \%$ of variance for leg press. Adding age to the equation did not increase $R^{2}$ in any of the previous models. Similarly, adding WBLH FM to the equation did not significantly increase $\mathrm{R}^{2}$ in any of the previous models, with the exception of leg press $(+8.7 \%, \mathrm{P}=0.016)$ the resulting equation being: leg press $=-550.4+(5.614 \times$ chest $)+(6.132 \times$ corrected thigh $)+(-0.003 \times$ WBLH FM). When WBLH LST was used as the predictor, the explained variance for leg press was $31.6 \%(\mathrm{P}<0.001 ; \mathrm{SEE}=36.8 \mathrm{~kg})$ : using lower limbs LST as the predictor variable, the explained variance was $37.1 \%(\mathrm{P}<0.001$; SEE $=36.3$ $\mathrm{kg}$ ). In the equations reported in Table 5, the SEE for body composition variables and leg press test scores was $5-13 \%$ and about $16 \%$ of the mean measured value, respectively. For all models, the DurbinWatson statistics was between 1.5 and 2.5, indicating that autocorrelation was not present in the residuals; VIF values for predictor variables were $<4$ and the Koenker test was $>0.05$, indicating that models are robust to collinearity and heteroscedasticity.

Table 4. Bivariate correlations (Spearman's $\rho$ ) between BCs, DXA-measured body composition, and muscle strength test scores in the study participants.

\begin{tabular}{|c|c|c|c|c|c|c|c|c|c|c|}
\hline \multirow[b]{2}{*}{ Variable } & \multicolumn{10}{|c|}{ Body circumference $(\mathrm{cm})$} \\
\hline & Arm & Corrected arm & Wrist & Thigh & Corrected thigh & Calf & Corrected calf & Chest & Waist & Hip \\
\hline \multicolumn{11}{|l|}{ Lean soft tissue (LST) } \\
\hline Upper limbs LST (g) & 0.154 & 0.259 & $0.692^{\star * *}$ & -0.270 & -0.212 & -0.138 & 0.266 & $0.513^{*}$ & $0.515^{*}$ & -0.188 \\
\hline Lower limbs LST (g) & $0.449^{*}$ & $0.398^{* 0}$ & 0.289 & $0.479^{*}$ & $0.502^{*}$ & $0.472^{*}$ & 0.340 & $0.451^{*}$ & $0.518^{*}$ & $0.562^{*}$ \\
\hline Appendicular LST (g) & $0.416^{*}$ & $0.406^{* \circ}$ & $0.448^{\star \circ}$ & 0.312 & 0.348 & 0.346 & 0.360 & $0.526^{*}$ & $0.582^{* *}$ & $0.405^{*}$ \\
\hline \multicolumn{11}{|l|}{ Bone mineral content (BMC) } \\
\hline WBLH BMC (g) & $0.462^{*}$ & $0.543^{*}$ & $0.319 \S$ & 0.168 & 0.146 & 0.187 & 0.086 & $0.511^{*} \S$ & 0.360 & 0.368 \\
\hline Upper limbs BMC (g) & 0.193 & 0.376 & $0.387^{*} \S$ & -0.224 & -0.189 & -0.097 & 0.087 & 0.287 & 0.130 & -0.237 \\
\hline Lower limbs BMC (g) & $0.394^{*}$ & $0.444^{*}$ & 0.243 & 0.187 & 0.146 & 0.244 & 0.085 & $0.454^{*} \S$ & 0.304 & 0.346 \\
\hline Appendicular BMC (g) & 0.374 & $0.467^{*}$ & $0.308 \S$ & 0.086 & 0.063 & 0.169 & 0.063 & $0.449 * \S$ & 0.283 & 0.210 \\
\hline \multicolumn{11}{|l|}{ Bone mineral density (BMD) } \\
\hline WBLH BMD $\left(\mathrm{g} / \mathrm{cm}^{2}\right)$ & $0.468^{*}$ & $0.470^{*}$ & 0.150 & 0.250 & 0.175 & 0.216 & -0.014 & $0.559^{\star} \S$ & $0.460 * \S$ & $0.510^{*}$ \\
\hline Upper limbs BMD $\left(\mathrm{g} / \mathrm{cm}^{2}\right)$ & $0.500^{*}$ & $0.412^{* 0}$ & $0.316 \S$ & $0.475^{\star} \S$ & $0.424^{*}$ & 0.355 & -0.008 & $0.467^{*} \S$ & $0.456^{*} \S$ & $0.637^{* * *} \S$ \\
\hline Lower limbs BMD $\left(\mathrm{g} / \mathrm{cm}^{2}\right)$ & $0.409^{*}$ & 0.358 & $0.098 \S$ & 0.226 & 0.116 & 0.188 & -0.153 & $0.517^{*} \S$ & $0.473^{*} \S$ & $0.457^{*}$ \\
\hline Appendicular BMD $\left(\mathrm{g} / \mathrm{cm}^{2}\right)$ & $0.480^{*}$ & $0.395^{* \circ}$ & 0.152 & 0.359 & 0.255 & 0.297 & -0.100 & $0.449^{*} \S$ & $0.506^{*} \S$ & $0.604^{* *}$ \\
\hline \multicolumn{11}{|l|}{ Strength test } \\
\hline Leg press score $(\mathrm{kg})$ & $0.411^{*}$ & $0.453^{* \circ}$ & 0.154 & 0.285 & 0.296 & 0.169 & 0.131 & $0.582^{* *} \S$ & $0.491 * \S$ & 0.312 \\
\hline
\end{tabular}

${ }^{*}, \mathrm{P}_{\mathrm{c}}<0.05$; ${ }^{* *}, \mathrm{P}_{\mathrm{c}}<0.01 ;{ }^{* * *}, \mathrm{P}_{\mathrm{c}}<0.001 ; \mathrm{P}_{c}$, Benjamini-Hochberg corrected p-value; ${ }^{\circ}$, correlation no longer significant after adjusting for age; $\S$, correlation improving/appearing after adjusting for age; WBLH, Whole-Body Less Head
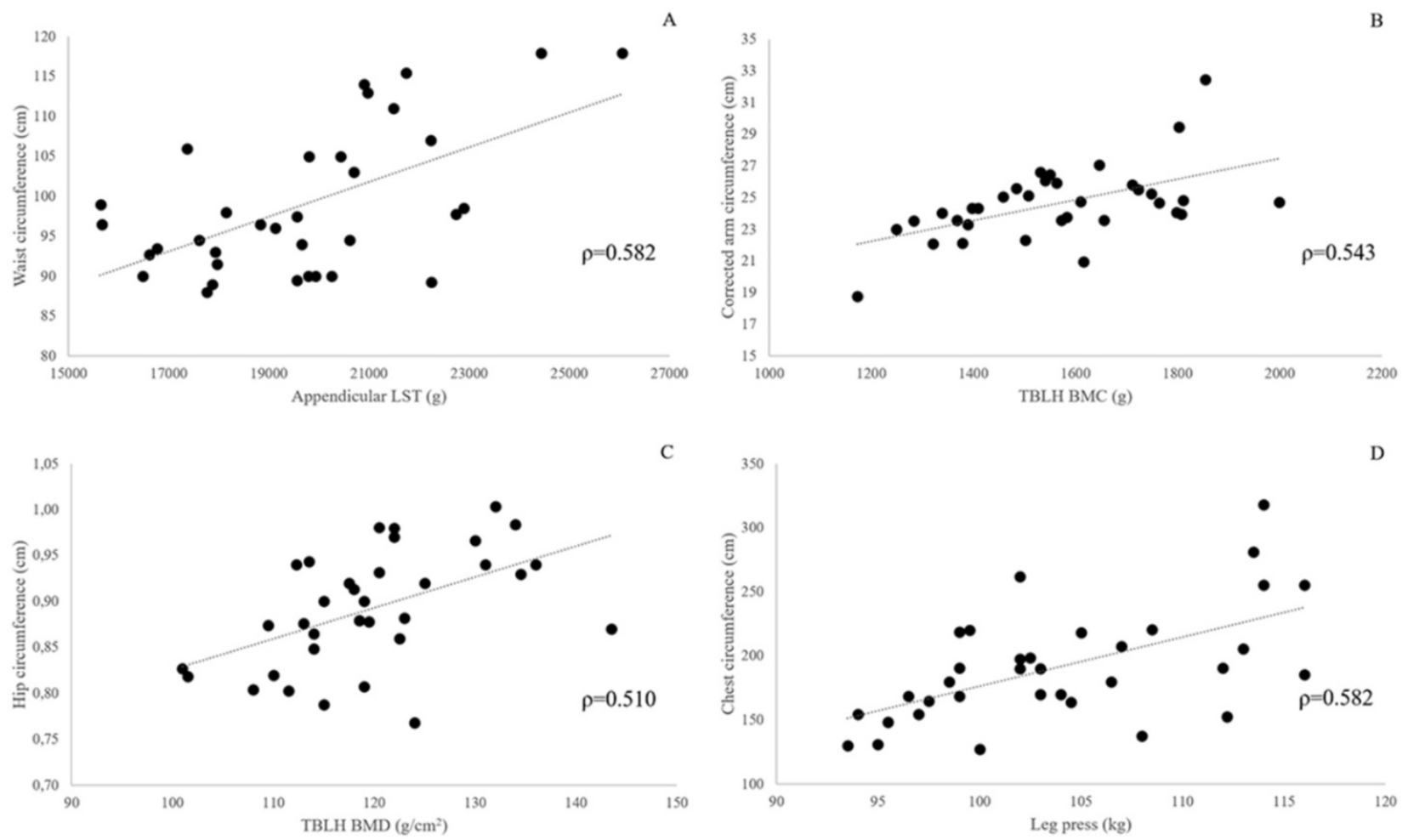

Figure 2. Panels A-D: scatterplots showing the association between selected body composition and strength test outcomes, and body circumferences in 34 obese females. All correlations are statistically significant at Benjamini-Hochberg corrected P-value $<0.01$. 
Table 5. Results of stepwise linear regression analysis using DXA-measured body composition and lower limbs strength tests outcomes as the dependent variable and body circumferences as predictor variable(s).

\begin{tabular}{|c|c|c|c|c|c|c|}
\hline Dependent variable & Predictor variable & Adjusted R² & Constant & B coefficient & SEE & P-value \\
\hline \multicolumn{7}{|l|}{ Lean soft tissue (LST) } \\
\hline Upper limbs LST & wrist & 0.462 & -2826.380 & 440.295 & 542.4 & $<0.001$ \\
\hline Lower limbs LST & waist, corrected thigh & 0.504 & -5996.850 & $116.908,202.234$ & 1411.9 & $<0.001$ \\
\hline Appendicular LST & waist & 0.318 & 4283.673 & 155.779 & 2014.2 & $<0.001$ \\
\hline \multicolumn{7}{|c|}{ Bone mineral content (BMC) } \\
\hline WBLH BMC & corrected arm & 0.273 & 448.618 & 45.304 & 167.2 & 0.001 \\
\hline Upper limbs BMC & wrist & 0.123 & 88.295 & 12.060 & 33.9 & 0.024 \\
\hline Lower limbs BMC & chest & 0.181 & 18.382 & 6.771 & 91.3 & 0.007 \\
\hline Appendicular BMC & corrected arm & 0.194 & 339.661 & 24.858 & 112.3 & 0.005 \\
\hline \multicolumn{7}{|c|}{ Bone mineral density (BMD) } \\
\hline WBLH BMD & chest, hip & 0.413 & 0.151 & $0.004,0.003$ & 0.0485 & $<0.001$ \\
\hline Upper limbs BMD & hip & 0.387 & 0.368 & 0.637 & 0.0346 & $<0.001$ \\
\hline Lower limbs BMD & chest, hip & 0.333 & 0.155 & $0.005,0.003$ & 0.0691 & 0.001 \\
\hline Appendicular BMD & hip, waist & 0.428 & 0.276 & 0.0030 .002 & 0.0514 & $<0.001$ \\
\hline \multicolumn{7}{|l|}{ Strength test } \\
\hline Leg press & chest, corrected thigh & 0.431 & -378.904 & $4.063,3.117$ & 33.54 & $<0.001$ \\
\hline
\end{tabular}

$\mathrm{R}^{2}$, coefficient of determination; $\mathrm{SEE}$, standard error of the estimate.

\section{Discussion}

To the best of our knowledge, this is the first study investigating the relationships between BCs, DXA-measured lean mass components, and muscle strength in obese females. Results indicate that:

- Several statistically significant correlations are present between BCs and LST mass, BMC and $\mathrm{BMD}$ as well as performance in the leg press test.

- Body circumference has better potential in predicting muscle mass and strength than bone characteristics.

Our first hypothesis explored in this study was that relationships exist in obesity between BCs and lean mass components, and muscle strength. Results confirmed such a hypothesis by showing, in a sample of women encompassing a similar number of Class I, Class II, and Class III obese participants, several positive statistically significant correlations between DXA-measured lean mass variables and strength tests scores, and several BCs (Table 4). This indicates that in obese females increasing BCs generally reflect increasing amounts of lean soft mass and mineral mass, and higher muscle strength. Such an association was essentially independent of age, suggesting that it is inherent to the obese condition. A second hypothesis tested in this work was that BCs are able to predict lean mass variables and muscle strength. Results partially confirmed such hypothesis by showing that BCs are better predictors of muscle- than bone-related variables. Overall, findings indicate that BCs have potential as reliable predictors of selected lean mass components and strength test performance in obesity and prompt for further studies in a larger number of obese individuals of both sexes.

In this study appendicular LST mass, a proxy of body skeletal muscle [3, 12, 13], was measured with an accurate method such as DXA [44]. Correlation analysis (Table 4) showed that in our sample of obese females, trunk circumferences are more representative of bodily skeletal muscle than limbs circumferences even after skinfold correction, despite trunk circumferences perimetering a substantial amount of visceral organ and fat tissue in addition to LST. This is in agreement with previous findings in heterogeneous populations showing that limb anthropometry may be inaccurate in estimating muscle cross-sectional area with increasing limb adiposity [46-48]. In the obese females participating in this study, DXA-measured trunk mass was about $50 \%$ of body mass (Table 2), these two variables showing almost perfect correlation $(\rho=0.91)$.

Accordingly, it seems that the bodily skeletal muscle complement of obese females is more proportional to body mass than regional mass, independently of loading. Our results are supported by data [48] obtained in 110 middle age Korean diabetic women (age range 40-60 y; BMI $27.2 \pm 2.7$ $\mathrm{kg} / \mathrm{m}^{2}$ ) showing small to moderate (albeit statistically significant) correlation between arm and thigh circumference, and DXA-measured TB LST mass ( $\mathrm{r}=$ $0.368, \mathrm{P}<0.001 ; \mathrm{r}=0.226 ; \mathrm{P}=0.025)$. Unfortunately, the authors did not present results of correlation analysis between LST variables and another measurement taken in their work namely, the waist circumference thereby preventing more extensive comparison of theirs [48] and the current results. In the present study the wrist circumference more strongly correlated with upper arms LST $\left(\rho=0.692 ; P_{c}\right.$ $<0.001)$ than any other circumference and the wrist circumference was the only circumference showing significant correlation with upper limbs BMC, albeit at the limit of statistical significance. The wrist circumference is traditionally used to calculate body-frame size [49] because it is relatively devoid of subcutaneous fat and skeletal muscle, but its 
relationship with regional skeletal muscle or mineral mass is not established. Since wrist circumference has been considered a possible risk factor for developing diabetes, metabolic syndrome and cardiovascular disease [50, 51] the relationships between wrist circumference and skeletal and mineral muscle mass in obesity deserve further investigation.

BCs were able to predict limb LST mass, explaining about 32 to $50 \%$ of in-sample variance (adjusted R2, 0.318 - 0.504; Table 5). The SEE for appendicular LST mass was about $2.0 \mathrm{~kg}$ i.e., $10.1 \%$ of the mean DXA-measured value (Table 2). This result compares well with that obtained in larger groups of young adult non-obese males and females [52-54]. Estimation of appendicular LST mass in obesity is of interest because it is significantly associated with insulin levels in overweight or obese women, independently of age, body size or fat mass [55] and increasing skeletal muscle is associated with decreased insulin sensitivity [56]. Accordingly, the proposed predictive equation could be of use in the non-invasive evaluation of skeletal muscle during weight change.

Correlation analysis (Table 4) showed that upper body circumferences are more representative of the local and bodily amounts of bone mineral in obese females than that of the lower body, suggesting that the association between BMC and BCs is independent of loading. At variance, lower limb circumferences showed stronger average correlation with regional and WBLH DXA-measured FM and \%FM than upper limb circumferences (not shown). Therefore, it can be hypothesized that higher BMC in obese females is largely independent of regional and body FM. Upper arm circumferences were prevalently selected as predictors of $\mathrm{BMC}$ in regression analysis (Table 5) in accordance to the higher strength found in correlation analysis (Table 4). However, the ability of BCs to predict $B M C$ was limited (adjusted $\mathrm{R}^{2}$ ranging from 0.123 to 0.273 ), the SEE for WBLH BMC being about $11 \%$ of the mean DXA-measured value indicating that the relevant anthropometric predictive equation should be used with caution in individual. In our sample of obese females, the chest and/or hip circumference showed strongest correlation with BMD variables (Table 4) indicating that body tissue perimetered in the trunk is more representative of WBLH and regional BMD than that in the limbs. The hip circumference was the only common predictor for all BMD outcomes in regression analysis, the chest circumference being selected as an additional predictor in two out of four equations (Table 5).

These findings are supported by previous data showing that hip circumference was more strongly associated with BMD at both the femoral neck and lumbar spine site than BMI, waist circumference, body FM and appendicular FM in a large number of obese males and females [57]. The SEE for WBLH BMD was about $5 \%$ of the mean DXA-measured value, which is reasonable accuracy. The explained variance was generally higher than that obtained for BMD at several key body sites using age and anthropometry in adult females [27]. Accordingly, the anthropometric predictive equations presented herein would be of some use in estimating the BMD of obese females.

The relationship between obesity and muscle strength is controversial. It has been shown that muscle strength is closely related to the absolute amount of skeletal muscle [58, 59] the latter being frequently increased in obese persons, and it has been hypothesized that weight bearing and supporting of the larger body mass have a training effect in the obese [60]. Other works showed a negative impact on skeletal muscle from adolescence [61] to old adulthood [24]. Findings on the relationship between muscle strength and anthropometric measurements such as BMI and body fat percentage were also inconclusive. Work investigating the effect of obesity on muscle strength over a wide range of ages showed that absolute strength is increased in obese vs. non-obese individuals, strength being lower in the lower limbs musculature when normalized to total body mass (review in [62]). In the current work, the strength of the correlation between thigh circumference and leg press was about half of that with the chest and waist circumference (Table 4). A similar correlation between thigh circumference and 1-RM leg press $(r=0.276)$ was found in a previous work carried out in obese females [48]. The correlation between corrected thigh, calf and corrected calf circumference, and leg press scores was even lower ( $\rho$ ranging from 0.131 to 0.296 ). Overall, these data strongly suggest that lower limb circumferences are not very representative of lower limbs muscle strength in obese females. Accordingly, in obese females a weak association ( $r, 0.29-0.49)$ has been found between lower limbs strength and fat-free mass [63-65]. Further support to this suggestion comes from the similarity between the strength of correlation between upper limbs and trunk BCs, and leg press scores presented in the current work (Table 4) and that found between maximal voluntary torque of the lower limbs, and body and lower limbs fat free mass $(\mathrm{r}=0.46$ and $\mathrm{r}=0.57$, respectively) in a larger sample $(\mathrm{n}=132)$ of obese male and female patients (mean age $=40.5 \pm 9.79 \mathrm{y}$, mean body mass $=126.13 \pm 19.64 \mathrm{~kg}$ ) [66]. In our sample, no statistically significant correlation was found between $\mathrm{BCs}$ and relative muscle strength (leg press score/whole body mass or 
leg press score/LST mass) even after adjusting for age, showing that $\mathrm{BCs}$ are not suitable for predicting relative muscle strength in obesity. While lower relative muscle strength has been consistently found in obese vs. non-obese persons (review in [62]), little attention has been given to differences in relative muscle strength within the obese population, apart when sarcopenic obesity is present. In this work involving non-sarcopenic participants spanning a wide range body weights, the lack of correlation between $\mathrm{BCs}$ and relative muscle strength even after adjusting for age suggests that lower limbs muscles were able to generate similar strength per unit body mass or unit lean mass in obese women irrespective of age. This prompts for more detailed investigation of skeletal muscle function in the obese population.

$\mathrm{BC}$ revealed able to predict leg press scores with some accuracy (adjusted $\mathrm{R}^{2}=0.431$; $\mathrm{SEE}=4.0 \%$ of the mean DXA-measured value). In normal weight females [67] anthropometry was able to predict bench press scores with a maximum $\mathrm{R}^{2}=0.410$ and $\mathrm{SEE}=5.4$ $\mathrm{kg}(18.9 \%$ of mean bench press score). In 39 premenopausal women aged $36 \pm 8$ y [69] a moderate, significant correlation $(\mathrm{r})$ was found between plantar flexor maximum voluntary contraction and calf circumference $(\mathrm{r}=0.584)$ and estimated muscle + bone cross-sectional area $(r=0.447)$. In linear regression analysis, $\mathrm{R}^{2}$ was 0.341 and 0.199 when the predictor was the calf circumference and the estimated muscle + bone cross-sectional area, respectively $(\mathrm{P}<0.05$ for both; SEE not available). Comparing the results of the present study with literature data, it is concluded that anthropometry is better able to predict muscle strength in obese than normal weight females. In our sample, BCs predicted leg press scores better than WBLH LST and lower limbs LST (explained variance $=43.1 \%$ and SEE $33.54 \mathrm{~kg} ; 31.6 \%$ and $36.8 \mathrm{~kg} ; 37.1 \%$ and $36.3 \mathrm{~kg}$, respectively).

In agreement with the maintenance of most of the statistically significant correlations between BCs, and body composition and strength test scores after adjusting for age (Table 4), adding age to the developed predictive equations presented in Table 5 did not significantly change $R^{2}$, indicating that equations are suitable for use across several decades of obese women chronological age.

In this preliminary work sample size was limited and the developed predictive equations were not validated in an independent sample. This obviously limits the generalized use of equations in the obese female population; moreover, we were not able to control for habitual physical activity in participants. However, the number of obese Class I, Class II, and Class III participants was roughly similar in the sample and the means, standard deviations, and ranges shown in Table 1 for age, weight and anthropometric measures indicate that participants were heterogeneous enough for the development of non-population specific regression equations. As participants spanned a relatively large age range (3561 years) and aging is associated with a decrease in maximal muscle force [69], this may have confounded any effect of obesity on skeletal muscle force. However, no participant was sarcopenic $(\mathrm{SMM}=6.26$ or higher) and no significant difference between participants aged below and above the sample median age $(48 \mathrm{y})$ was found in the outcome of leg press test, suggesting that age had a limited effect on results.

\section{Conclusion}

In conclusion, this work demonstrated in obese females that increasing BCs positively correlate with skeletal muscle mass and strength as well as mineral bone, and BCs are suitable to estimate several such variables. Accordingly, BCs represent a promising tool for estimating skeletal muscle, muscle strength and bone health variables when direct measurements are not available/feasible. Further work in larger samples of obese females and in obese males is needed to generalize the proposed predictive anthropometric in the obese population.

\section{Acknowledgements}

This work was supported in part by intramural funding to C. Zancanaro and C. Milanese.

The authors warmly thank all participants for volunteering in this work. The help of Dr. MG Zenti and Prof. P. Moghetti in recruiting participants is gratefully acknowledged.

\section{Author Contributions}

$\mathrm{CM}$ conceived the work, performed measurements, analyzed and interpreted data, drafted the paper; VC performed and collected measurements, analyzed and interpreted data, produced figure, drafted the paper; $\mathrm{CZ}$ conceived the work, analyzed and interpreted data, drafted the paper. All authors read and approved the final version of the paper.

\section{Competing Interests}

The authors have declared that no competing interest exists.

\section{References}

1. Müller MJ, Bosy-Westphal A, Kutzner D, Heller M. Metabolically active components of fat-free mass and resting energy expenditure in humans: recent lessons from imaging technologies. Obes Rev. 2002; 3:113-22.

2. Snyder WS, Cook MJ, Nasset ES, Karhausen LR, Howells GP, Tipton IH. Report of the task group on reference man. Oxford UK: Pergamon; 1975 (Inl Commission on Radiological Protection No.23). 
3. Kim J, Wang Z, Heymsfield SB, Baumgartner RN, Gallagher D. Total-body skeletal muscle mass: estimation by a new dual-energy $X$-ray absorptiometry method. Am J Clin Nutr. 2002; 76:378-83.

4. Delmonico MJ, Harris TB, Visser M, Park SW, Conroy MB, Velasquez-Mieyer P, Boudreau R, Manini TM, Nevitt M, Newman AB, Goodpaster BH. Health, Aging, and Body. Longitudinal study of muscle strength, quality, and adipose tissue infiltration. Am J Clin Nutr. 2009; 90:1579-85. doi: 10.3945/ajcn.2009.28047

5. Forhan M, Gill SV. Obesity, functional mobility and quality of life. Best Pract Res Clin Endocrinol Metab. 2013; 27:129-37. doi: 10.1016/j.beem.2013.01.003.

6. Barbat-Artigas S, Pion CH, Leduc-Gaudet JP, Rolland Y, Aubertin-Leheudre M. Exploring the role of muscle mass, obesity, and age in the relationship between muscle quality and physical function. J Am Med Dir Assoc. 2014; 15:303.e13-20. doi: 10.1016/j.jamda.2013.12.008

7. Neder JA, Nery LE, Shinzato GT, Andrade MS, Peres C, Silva AC. Reference values for concentric knee isokinetic strength and power in nonathletic men and women from 20 to 80 years old. J Orthop Sports Phys Ther. 1999; 29:116-26.

8. Albala C, Yáñez M, Devoto E, Sostin C, Zeballos L, Santos JL. Obesity as a protective factor for postmenopausal osteoporosis. Int J Obes Relat Metab Disord. 1996; 20:1027-32.

9. Sievänen H. Bone: impact loading-nature's way to strengthen bone. Nat Rev Endocrinol. 2012; 8:391-3. doi: 10.1038/nrendo.2012.88.

10. Reid IR. Fat and bone. Arch Biochem Biophys. 2010; 503:20-7. doi: 10.1016/j.abb.2010.06.027.

11. Kim YM, Kim SH, Kim S, Yoo JS, Choe EY, Won YJ. Variations in fat mass contribution to bone mineral density by gender, age, and body mass index: the Korea National Health and Nutrition Examination Survey (KNHANES) 2008-2011. Osteoporos Int. 2016; 27:2543-54. doi: 10.1007/s00198-016-3566-y.

12. Shih R, Wang Z, Heo M, Wang W, Heymsfield SB. Lower limb skeletal muscle mass: development of dual-energy $\mathrm{X}$-ray absorptiometry prediction model. J Appl Physiol (1985). 2000; 89:1380-6.

13. Zhao X, Wang Z, Zhang J, Hua J, He W, Zhu S. Estimation of total body skeletal muscle mass in Chinese adults: prediction model by dual-energy X-ray absorptiometry. PLoS One. 2013 8:e53561. doi: 10.1371/journal.pone.0053561.

14. Danneels LA, Vanderstraeten GG, Cambier DC, Witvrouw EE, Bourgois J, Dankaerts W, De Cuyper HJ. Effects of three different training modalities on the cross-sectional area of the lumbar multifidus muscle in patients with chronic low back pain. Br J Sports Med. 2001; 35:186-91. doi: 10.1136/bjsm.35.3.186

15. Chen MM, Lear SA, Gao M, Frohlich JJ, Birmingham CL. Intraobserver and interobserver reliability of waist circumference and the waist-to-hip ratio. Obes Res. 2001; 9:651.

16. Bray GA, Gray DS. Obesity. Part I-Pathogenesis. West J Med. 1988; 149:429-41.

17. Jelliffe DB. The assessment of the nutritional status of the community (with special reference to field surveys in developing regions of the world). Monogr Ser World Health Organ. 1966; no.53.

18. Heymsfield S, Lohman T, Wang ZM, Going S. Human Body Composition. 2005. $2^{\text {nd }}$ edition. Human Kinetics, Champaign Ill.

19. Doupe MB, Martin AD, Searle MS, Kriellaars DJ, Giesbrecht GG. A new formula for population-based estimation of whole body muscle mass in males. Can J Appl Physiol. 1997; 22:598-608.

20. Martin AD, Spenst LF, Drinkwater DT, Clarys JP. Anthropometric estimation of muscle mass in men. Med Sci Sports Exerc. 1990; 22:729-33.

21. Lee RC, Wang Z, Heo M, Ross R, Janssen I, Heymsfield SB. Total-body skeletal muscle mass: development and cross-validation of anthropometric prediction models. Am J Clin Nutr. 2000; 72:796-803. Erratum in: Am J Clin Nutr. 2001; 73.995.

22. Baumgartner RN, Koehler KM, Gallagher D, Romero L, Heymsfield SB, Ross RR, Garry PJ, Lindeman RD. Epidemiology of sarcopenia among the elderly in New Mexico. Am J Epidemiol. 1998; 147:755-63. Erratum in: Am J Epidemiol. 1999; 149:1161.

23. Janssen I, Heymsfield SB, Wang ZM, Ross R. Skeletal muscle mass and distribution in 468 men and women aged 18-88 yr. J Appl Physiol (1985). 2000; 89:81-8. Erratum in: J Appl Physiol (1985). 2014; 116:1342.

24. Rolland Y, Lauwers-Cances V, Pahor M, Fillaux J, Grandjean H, Vellas B. Muscle strength in obese elderly women: effect of recreational physical activity in a cross-sectional study. Am J Clin Nutr. 2004; 79:552-7.

25. Pereira PM, da Silva GA, Santos GM, Petroski EL, Geraldes AA. Development and validation of anthropometric equations to estimate appendicular muscle mass in elderly women. Nutr J. 2013; 12:92. doi: 10.1186/1475-2891-12-92.

26. Simões M, Severo M, Oliveira A, Ferreira I, Lopes C. Predictive equations for estimating regional body composition: a validation study using DXA as criterion and associations with cardiometabolic risk factors. Ann Hum Biol. 2016; 43:219-28. doi: 10.3109/03014460.2015.1054427.

27. Slemenda CW, Hui SL, Williams CJ, Christian JC, Meaney FJ, Johnston CC Jr. Bone mass and anthropometric measurements in adult females. Bone Miner. 1990; 11:101-9.

28. Miller JZ, Slemenda CW, Meaney FJ, Reister TK, Hui S, Johnston CC. The relationship of bone mineral density and anthropometric variables in healthy male and female children. Bone Miner. 1991; 14:137-52.

29. Adams WC, Deck-Côté K, Winters KM. Anthropometric estimation of bone mineral content in young adult females. Am J Hum Biol. 1992; 4:767-774. doi: 10.1002/ajhb.1310040608.
30. Singh R, Gupta S. Relationship of calf circumference with bone mineral density and hip geometry: a hospital-based cross-sectional study. Arch Osteoporos. 2015; 10:17. doi: 10.1007/s11657-015-0221-8.

31. Douchi T, Yamamoto S, Oki T, Maruta K, Nakamura S, Nagata Y. Association of upper arm circumference at muscle flexion with lumbar spine bone mineral density. J Bone Miner Metab. 2000; 18:18-21.

32. Cui LH, Shin MH, Kweon SS, Choi JS, Rhee JA, Lee YH, Nam HS, Jeong SK, Park KS, Ryu SY, Choi SW. Sex-related differences in the association between waist circumference and bone mineral density in a Korean population. BMC Musculoskelet Disord. 2014; 2, 15:326. doi: 10.1186/1471-2474-15-326.

33. Lohman TG, Roche AF, Martorell R. Anthropometric standardization reference manual. 1988. Human Kinetics, Champaign, IL.

34. Norton K, Olds T. Anthropometrica. 1996. Sydney, Australia: UNSW Press.

35. Prentice A, Parsons TJ, Cole TJ. Uncritical use of bone mineral density in absorptiometry may lead to size-related artifacts in the identification of bone mineral determinants. Am J Clin Nutr. 1994; 60:837-42.

36. Bolotin HH, Sievänen $H$, Grashuis JL, Kuiper JW, Järvinen TL. Inaccuracies inherent in patient-specific dual-energy X-ray absorptiometry bone mineral density measurements: comprehensive phantom-based evaluation. Bone Miner Res. 2001; 16:417-26.

37. Turner AS, Maillet JM, Mallinckrodt C, Cordain L. Bone mineral density of the skull in premenopausal women. Calcif Tissue Int. 1997; 61:110-3.

38. Brismar TB, Ringertz J. Effect of bone density of the head on total body DEXA measurements in 100 healthy Swedish women. Acta Radiol. 1996; 37:101-6.

39. Brzycki M. Strength testing: predicting a one-rep max from reps-to-fatigue. J Health Phys Educ Rec Dance. 1993; 64:88-90.

40. Hopkins, W.G. Internet Society for Sports Science. A scale of magnitude for effect statistics. 2009. Available: http://www.sportsci.org/resource/ stats/index.html

41. Benjamini $Y$, Hochberg Y. Controlling the false discovery rate: a practical and powerful approach to multiple testing. J Royal Stat Soc, Series B. 1995; 57: 289300.

42. Koenker R. A Note on Studentizing a Test for Heteroskedasticity, J Econometrics 1981; 17:107-12.

43. World Health Organization Consultation on Obesity, Obesity: Preventing and Managing the Global Epidemic: A Report of the WHO Consultation on Obesity, World Health Organization. Geneva, Switzerland; 1998.

44. Buckinx F, Landi F, Cesari M, Fielding RA, Visser M, Engelke K, Maggi S, Dennison E, Al-Daghri NM, Allepaerts S, Bauer J, Bautmans I, Brandi ML, Bruyère $\mathrm{O}$, Cederholm T, Cerreta F, Cherubini A, Cooper C, Cruz-Jentoft A, McCloskey E, Dawson-Hughes B, Kaufman JM, Laslop A, Petermans J, Reginster JY, Rizzoli R, Robinson S, Rolland Y, Rueda R, Vellas B, Kanis JA. Pitfalls in the measurement of muscle mass: a need for a reference standard. J Cachexia Sarcopenia Muscle. 2018; 9:269-278. doi: 10.1002/jcsm.12268

45. Buckley DC, Kudsk KA, Rose BS, Fatzinger P, Koetting CA, Schlatter M. Anthropometric and computerized tomographic measurements of lower extremity lean body mass. J Am Diet Assoc. 1987; 87:196-9.

46. Forbes GB, Brown MR, Griffiths HJ. Arm muscle plus bone area: anthropometry and CAT scan compared. Am J Clin Nutr. 1988; 47:929-31.

47. Jordão AA1, Bellucci AD, Dutra de Oliveira JE, Sérgio Marchini J. Midarm computerized tomography fat, muscle and total areas correlation with nutritional assessment data. Int J Obes Relat Metab Disord. 2004: 28:1451-5.

48. Kwon HR, Han KA, Ahn HJ, Lee JH, Park GS, Min KW. The Correlations between Extremity Circumferences with Total and Regional Amounts of Skeletal Muscle and Muscle Strength in Obese Women with Type 2 Diabetes. Diabetes Metab J. 2011; 35:374-83. doi: 10.4093/dmj.2011.35.4.374.

49. Peters DM and Eston R. Prediction and measurement of frame size in young adult males. J Sports Sci. 1993; 11:9-15.

50. Capizzi M, Leto G, Petrone A, Zampetti S, Papa RE, Osimani M, Spoletini M, Lenzi A, Osborn J, Mastantuono M, Vania A, Buzzetti R. Wrist circumference is a clinical marker of insulin resistance in overweight and obese children and adolescents. Circulation 2011; 123:1757-62.

51. Jahangiri Noudeh Y, Hadaegh F, Vatankhah N, Momenan AA, Saadat N, Khalili D, Azizi F. Wrist circumference as a novel predictor of diabetes and prediabetes: results of cross-sectional and 8.8-year follow-up studies. J Clin Endocrinol Metab. 2013; 98:777-84.

52. Holmes JD, Andrews DM, Durkin JL, Dowling JJ. Predicting in vivo soft tissue masses of the lower extremity using segment anthropometric measures and DXA. J Appl Biomech. 2005; 21:371-82.

53. Arthurs KL, Andrews DM. Upper extremity soft and rigid tissue mass prediction using segment anthropometric measures and DXA. J Biomech. 2009; 42:389-94. doi: 10.1016/j.jbiomech.2008.11.021.

54. Scafoglieri A, Tresignie J, Provyn S, Marfell-Jones M, Reilly T, Bautmans I, Clarys JP. Prediction of segmental lean mass using anthropometric variables in young adults. J Sports Sci. 2012; ):777-85. doi: $10.1080 / 02640414.2012 .670716$

55. Leon B, Jenkins S, Pepin K, Chaudhry H, Smith K, Zalos G, Miller BV 3rd, Chen KY, Remaley AT, Waclawiw MA, Sumner AE, Cannon RO 3rd. Insulin and extremity muscle mass in overweight and obese women. Int J Obes (Lond). 2013; 37:1560-4. doi: 10.1038/ijo.2013.45.

56. Albu JB, Kovera AJ, Allen L, et al. Independent association of insulin resistance with larger amounts of intermuscular adipose tissue and a greater acute insulin response to glucose in African American than in white nondiabetic women. Am J Clin Nutr. 2005; 82:1210-7. 
57. Yang S, Shen X. Association and relative importance of multiple obesity measures with bone mineral density: the National Health and Nutrition Examination Survey 2005-2006. Arch Osteoporos. 2015; 10:14. doi: 10.1007/s11657-015-0219-2.

58. Metter EJ, Lynch N, Conwit R, Lindle R, Tobin J, Hurley B. Muscle quality and age: cross-sectional and longitudinal comparisons. J Gerontol Biol Sci Med Sci. 1999; 54A: B207-18.

59. Newman AB, Haggerty CL, Goodpaster B, et al. Strength and muscle quality in a cohort of well-functioning older adults: The Health Aging and Body Composition Study. J Am Geriatr Soc. 2003; 51:323-30.

60. Miyatake N, Fujii M, Nishikawa H, Wada J, Shikata K, Makino H, Kimura I. Clinical evaluation of muscle strength in 20-79-years-old obese Japanese. Diabetes Res Clin Pract. 2000; 48:15-21.

61. Blimkie CJ, Sale DG, Bar-Or O. Voluntary strength, evoked twitch contractile properties and motor unit activation of knee extensors in obese and non-obese adolescent males. Eur J Appl Physiol Occup Physiol. 1990; 61:313-8.

62. Tomlinson DI, Erskine RM, Morse CI, Winwood K, Onambélé-Pearson G. The impact of obesity on skeletal muscle strength and structure through adolescence to old age. Biogerontology. 2016; 17:467-83. doi: $10.1007 /$ s10522-015-9626-4.

63. Hulens M, Vansant G, Lysens R, Claessens AL, Muls E, Brumagne S. Study of differences in peripheral muscle strength of lean versus obese women: an allometric approach. Int J Obes Relat Metab Disord. 2001; 25:676-81.

64. Maffiuletti NA, Jubeau M, Munzinger U, Bizzini M, Agosti F, De Col A Lafortuna CL, Sartorio A. Differences in quadriceps muscle strength and fatigue between lean and obese subjects. Eur J Appl Physiol. 2007; 10:51-9.

65. Segal NA, Zimmerman MB, Brubaker M, Torner JC. Obesity and knee osteoarthritis are not associated with impaired quadriceps specific strength in adults. PM R. 2011; 3:314-23; quiz 323. doi: 10.1016/j.pmrj.2010.12.011.

66. Gadducci AV, de Cleva R, de Faria Santarém GC, Silva PRS, Greve JMD, Santo MA. Muscle strength and body composition in severe obesity. Clinics (Sao Paulo). 2017; 72:272-275. doi: 10.6061/clinics/2017(05)03.

67. Scanlan JM, Ballmann KL, Mayhew JL, Lantz CD. Anthropometric dimensions to predict 1-RM bench press in untrained females. J Sports Med Phys Fitness. 1999; 39:54-60.

68. Bamman MM, Newcomer BR, Larson-Meyer DE, Weinsier RL, Hunter GR. Evaluation of the strength-size relationship in vivo using various muscle size indices. Med Sci Sports Exerc. 2000; 32:1307-13.

69. Morse CI, Thom JM, Davis MG, Fox KR, Birch KM, Narici MV. Reduced plantarflexor specific torque in the elderly is associated with a lower activation capacity. Eur J Appl Physiol. 2004; 92:219-26. 